\title{
The evaporation of the water-sodium chlorides solution droplets on the heated substrate
}

\author{
Evgenija Orlova, Geniy Kuznetsov, and Dmitriy Feoktistov
}

Department of Theoretical and Industrial Heat Systems Engineering, Institute of Power Engineering, Tomsk Polytechnic University, Tomsk, Russia

\begin{abstract}
This work presents an experimental study of the evaporation of a sessile water- sodium chlorides solution drop to open atmosphere on the solid substrate (anodized aluminum) under the varying heat flux. The main parameters defining drop profile were obtained: contact diameter, contact angle, height of the drop. The specific evaporation rate was calculated. The influence of the initial concentration of the evaporated solution to a value of the specific evaporation rate has been found out. The specific evaporation rate decreases with increasing of the concentration.
\end{abstract}

\section{Introduction}

Intensification of heat and mass transfer of an evaporating liquid droplet on a solid substrate is the basic perspective direction of thermal energy technology modernization in the design of high heat exchange systems.

Currently physical processes of droplet evaporation in the contact line "solid - liquid - gas" are insufficiently studied that prevents the development of technology in the chemical industry for drying liquid dispersions (pneumatic, spray, rotary, drum, spiral dryer), in aviation at solving "the problem of freezing aircrafts", in the mechanical engineering at designing heat engines, in medicine at the study of microstructures of DNA / RNA, in optoelectronics at the development of semiconductor lasers, lightemitting diodes.

Parameter that characterizes the process of droplet evaporation, in particular heat and mass transfer is the specific evaporation rate.

Heat and mass transfer processes at the phase transition of drops have been studied for a long time. In the experimental and numerical studies the dependences of the evaporation rate from the liquid vapor pressure [1], the radius of the droplet sphere [2], the initial temperature and the droplet size [3, 4], the temperature of the droplet surface [5], gas pressure and temperature of the surface [6], the contact angle [7], the contact radius [8], and properties of the wetting film of the surface [9, 10] have been estimated. However, all researches have been conducted using single-component liquids, acids, water, various alcohols and hydrocarbon compounds. It should be noted that researches of water-sodium chlorides solution droplet evaporation have been conducted recently. 


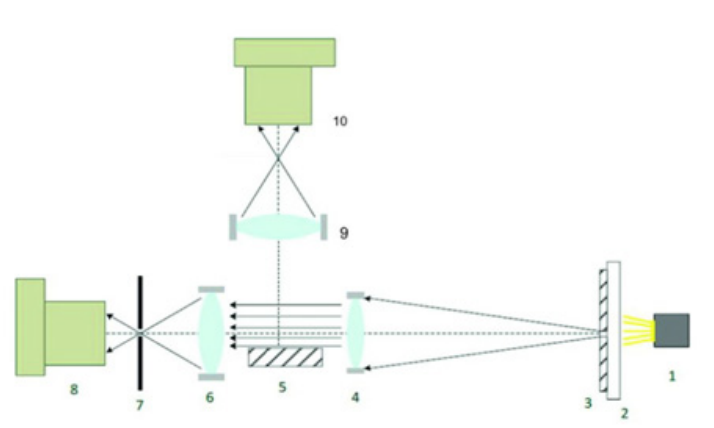

(a)

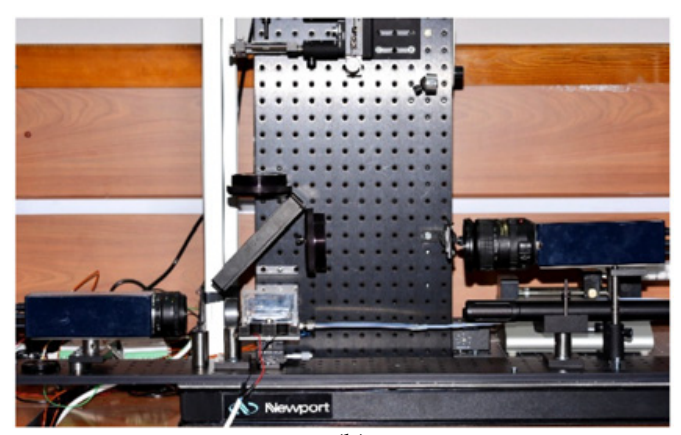

(b)

Figure 1. Schematic diagram (a) and photograph of the experimental setup (b): 1 - light source; 2 - clouded glass; 3 - hole; 4 - collimating lens; 5 - substrate; 6 - condensing lens; 7 - opaque shield with a hole; 8 - a high-speed video camera, 9 - lens; 10 - high-speed video camera.

An experimental study of the water solution of potassium acetate and sodium iodide droplet evaporation [11] at heating the substrate in the temperature range of $50-100{ }^{\circ} \mathrm{C}$ has been conducted.

It was found that the average evaporation rate of solutions is much less than the evaporation rate of the pure liquid at the same temperature. The characteristic curves of the average evaporation rate from the temperature of droplet surface have been obtained. These curves show that with increasing of salt concentration in the solution the average evaporation rate decreases.

It is known that the ringlike precipitate on the periphery of the drop is formed at crystallizing solution droplet evaporation. This effect is called "coffee ring" [12]. Physically, this phenomenon is explained in $[13,14]$ at conducting the experiments with the dispersed solids in the liquid.

However, nowadays there is a lack of understanding of heat and mass transfer processes under the conditions of the water-salt solution evaporation on a solid surface.

\section{Research technique}

The purpose of this paper is the experimental study of water saline solution droplet evaporation under the heating of a solid surface. In particular, it is necessary to assess the impact of the initial concentration, the temperature of a solid substrate on the specific evaporation rate. Also it is necessary to define the dynamics of change in the evaporation rate during the phase transition of the drop.

The researches have been conducted using experimental setup shown on Fig. 1. It consists of shadow and Schlieren systems [15-17].

The high-speed camera Fastvideo-500M was used in each system. This camera allows to record up to 500 frames per second with a resolution of $1280 \times 1024$ pixels. The heat of the substrate made of anodized aluminum (Fig. 2) was realized with a Peltier element (thermoelectric transducer type A-2TM 8.0-127/126-1.4 HR1).

It should be noted that the structure of the substrate surface is formed by concentrically arranged grooves (Fig. 2b).

Measuring of the temperature of the substrate was performed by eight-channel Agilent 34901A. Three thermocouples "chromel-copel" (Fig. 3) with measurement error $\pm 0.1^{\circ} \mathrm{C}$ were used as the temperature sensors.

Droplet evaporation was carried out in three modes of heating of the working area (Table 1).

According to results of the preliminary experiment the values of variable factors at three levels were defined (Table 2).

Recording of the experimental data (contact angle, contact radius, height) was carried out with using KRUSS program. The snapshots obtained during the experiment were processed by the program. 


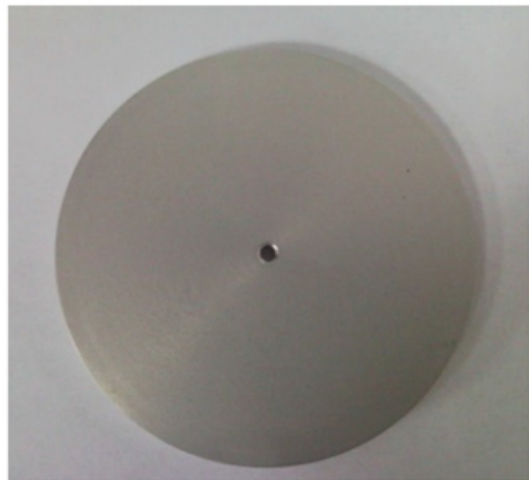

(a)

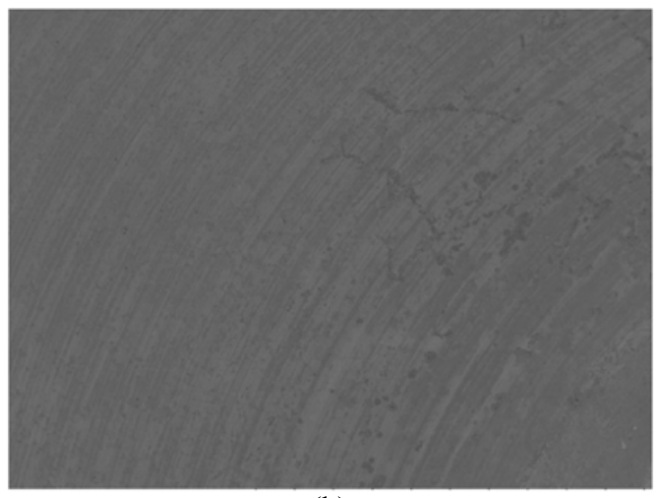

(b)

Figure 2. The substrate made of anodized aluminum: a) Magnification: $\times 1$; b) Magnification: $\times 100$.

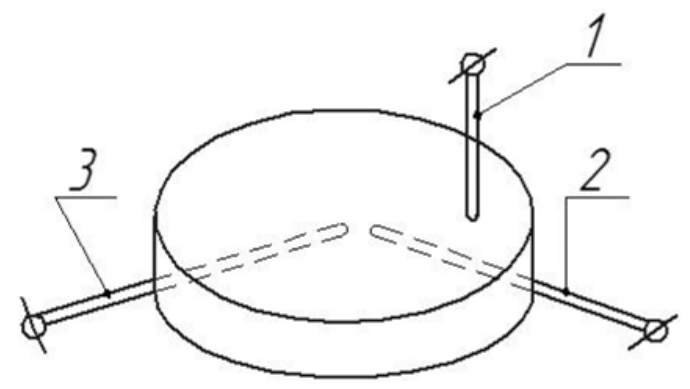

Figure 3. Arrangement of thermocouples: 1 - thermocouple fixed on the substrate surface; 2,3 - thermocouples fixed below the substrate.

Table 1. Parameters of studied substrates at different heating modes.

\begin{tabular}{|c|c|c|c|c|c|}
\hline Substrate & Heating modes & $\begin{array}{c}\text { Voltage } \\
\mathbf{U}, \mathbf{V}\end{array}$ & $\begin{array}{c}\text { Current } \\
\mathbf{I}, \mathbf{A}\end{array}$ & $\begin{array}{c}\text { Temperature under } \\
\text { the substrate } \\
\mathbf{t}_{\mathbf{w}}{ }^{\circ} \mathbf{C}\end{array}$ & $\begin{array}{c}\text { Temperature on } \\
\text { the substrate } \\
\mathbf{t}_{\mathbf{s}}{ }^{\circ} \mathbf{C}\end{array}$ \\
\hline \multirow{3}{*}{ Anodized aluminum } & I mode & 5 & 2.8 & 62.5 & 61.0 \\
\cline { 2 - 6 } & II mode & 6 & 3.2 & 73.5 & 72.9 \\
\cline { 2 - 6 } & III mode & 7 & 3.7 & 84.5 & 83.1 \\
\hline
\end{tabular}

The initial values of the curves plotted from the experimental data correspond to the time of placing a drop on the substrate. Recording of the investigated parameters was performed before formation of salt rings in the final stages of evaporation.

\section{Results and discussion}

The specific evaporation rate was determined by the following Eq. (1):

$$
E S=\frac{\left(V_{i}-V_{i+1}\right)}{\Delta t \cdot\left(A_{i}+A_{i+1}\right) / 2}, \quad \frac{m l}{s \cdot m m^{2}} .
$$

Where $V_{i}, A_{i}, V_{i+1}, A_{i+1}$ - are the volume and surface area of the droplet at the time $\mathrm{t}$ and $t_{i+1}$. 
Table 2. Variable factors.

\begin{tabular}{|l|c|c|c|}
\hline \multirow{2}{*}{ Factor } & \multicolumn{3}{|c|}{ Values of factors at levels } \\
\cline { 2 - 4 } & -1 & 0 & +1 \\
\hline Volume of drop V, ml & 0.02 & 0.04 & 0.06 \\
\hline Source voltage U, V & 5 & 6 & 7 \\
\hline Strength of current I, A & 2.8 & 3.2 & 3.7 \\
\hline Initial concentration of solution, \% (ppb mass) & 4.8 & 9.1 & 16.7 \\
\hline
\end{tabular}

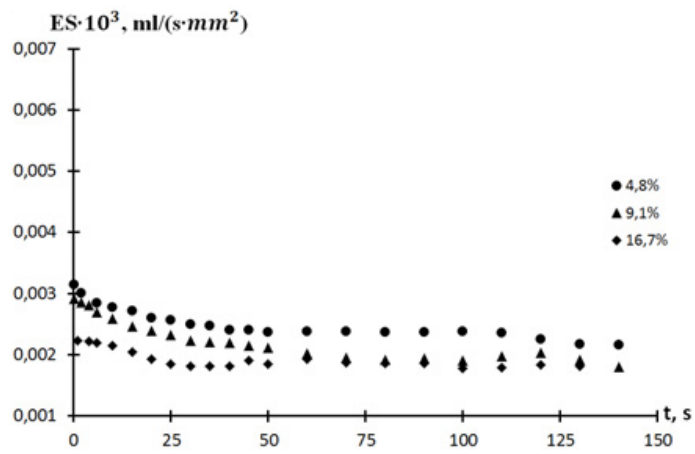

(a) $-\mathrm{U}=5 \mathrm{~V} ; \mathrm{I}=2.8 \mathrm{~A} ; \mathrm{t}_{\mathrm{w}}=62.5^{\circ} \mathrm{C} ; \mathrm{t}_{\mathrm{s}}=61^{\circ} \mathrm{C}$

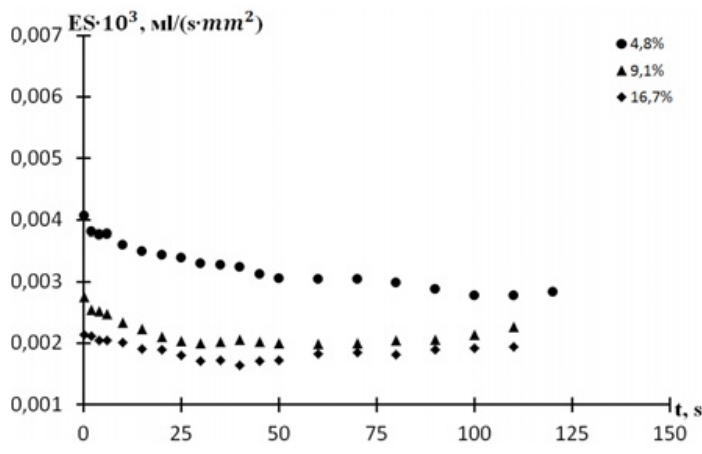

(b) $-\mathrm{U}=6 \mathrm{~V} ; \mathrm{I}=3.2 \mathrm{~A} ; \mathrm{t}_{\mathrm{w}}=73.5^{\circ} \mathrm{C} ; \mathrm{t}_{\mathrm{s}}=72.9^{\circ} \mathrm{C}$

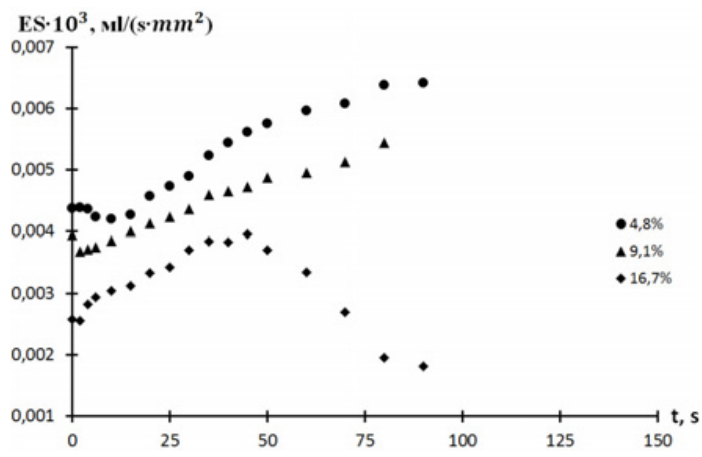

(c) $-\mathrm{U}=7 \mathrm{~V} ; \mathrm{I}=3.7 \mathrm{~A} ; \mathrm{t}_{\mathrm{w}}=84.5^{\circ} \mathrm{C} ; \mathrm{t}_{\mathrm{s}}=83.1^{\circ} \mathrm{C}$

Figure 4. Specific evaporation rate of water-sodium solution drop $(\mathrm{V}=0.02 \mathrm{ml} ; \mathrm{c}=4.8 \% ; 9.1 \% ; 16.7 \%)$ on substrate made of anodized aluminum.

Figures 4-6 demonstrates the calculated specific evaporation rate of the water-sodium chlorides solution droplets on the anodized aluminum. The volume of drops: $0.02 \mathrm{ml}, 0.04 \mathrm{ml}, 0.06 \mathrm{ml}$, the concentration of solution: $4.8 \% ; 9.1 \% ; 16.7 \%$. The drops evaporate at three heating modes.

According to the analysis of Figs. 4-6 the specific evaporation rate is decreased with increasing initial concentration of salt in solution. Similar conclusions were obtained in [11], but authors did not give an explanation for this effect. It is known, that the heat of vaporization increases with increasing concentrations of water-salt solution, and as a result the amount of heat needed for evaporation arises. This fact explains the decrease of the evaporation rate of droplets with high initial salt concentration.

It was found that the specific evaporation rate decreases (up to 30\%) in the evaporation process, then it increases. The calculated specific evaporation rate is in excellent agreement with the obtained results 


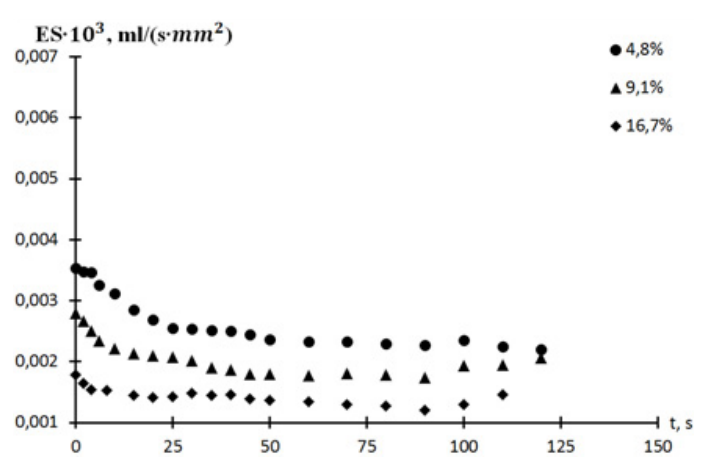

(a) $-\mathrm{U}=5 \mathrm{~V} ; \mathrm{I}=2.8 \mathrm{~A} ; \mathrm{t}_{\mathrm{w}}=62.5^{\circ} \mathrm{C} ; \mathrm{t}_{\mathrm{s}}=61^{\circ} \mathrm{C}$

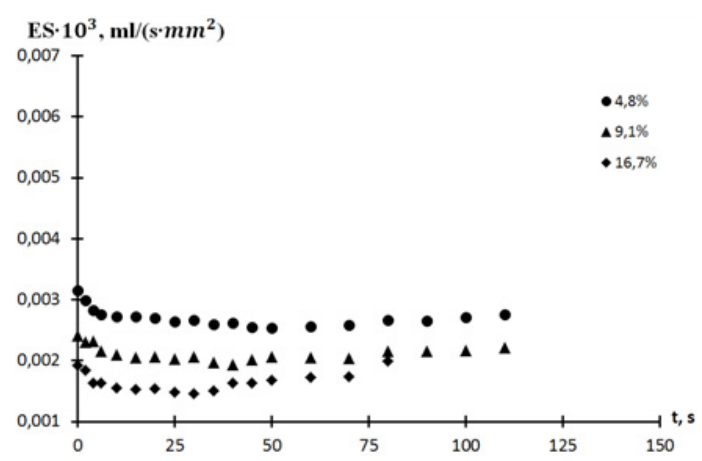

(b) $-\mathrm{U}=6 \mathrm{~V} ; \mathrm{I}=3.2 \mathrm{~A} ; \mathrm{t}_{\mathrm{w}}=73.5^{\circ} \mathrm{C} ; \mathrm{t}_{\mathrm{s}}=72.9^{\circ} \mathrm{C}$

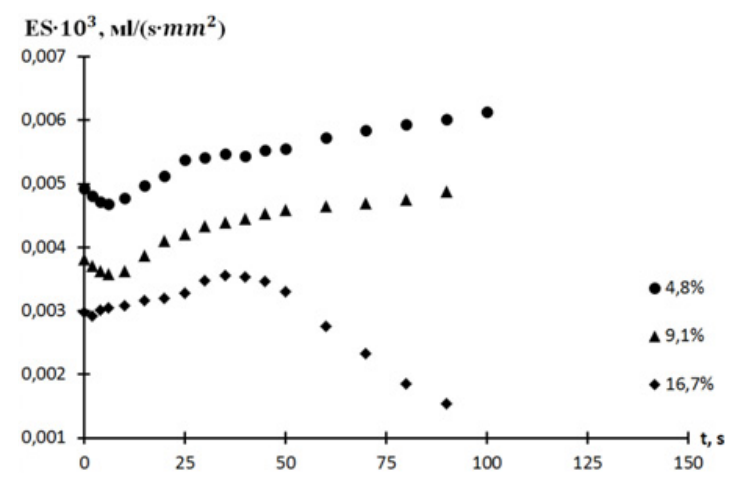

(c) $-\mathrm{U}=7 \mathrm{~V} ; \mathrm{I}=3.7 \mathrm{~A} ; \mathrm{t}_{\mathrm{w}}=84.5^{\circ} \mathrm{C} ; \mathrm{t}_{\mathrm{s}}=83.1^{\circ} \mathrm{C}$

Figure 5. Specific evaporation rate of water-sodium solution drop $(\mathrm{V}=0.04 \mathrm{ml} ; \mathrm{c}=4.8 \% ; 9.1 \% ; 16.7 \%)$ on substrate made of anodized aluminum.

for drops of distilled water $(104.7 \mathrm{ml})$, lying on a substrate with a surface temperature of $64{ }^{\circ} \mathrm{C}$ [8]. The difference is that in the final evaporation stage the specific evaporation rate of water-salt solutions doesn't increase so abruptly and doesn't reach values which higher than the specific evaporation rate at the initial evaporation stage. It should be noted that this dependence is indicative for water-salt solutions of $4.8 \%$ and $9.1 \%$ (Figs. $4-6(a-b)$ ).

It was found that the water-salt solution drops evaporation on the surface with temperatures $84.5^{\circ} \mathrm{C}$ differs from other cases. The initial stage of evaporation is defined by brief reducing of the specific evaporation rate (5-10 seconds), and then it increases monotonically (Figs. 4-6 (c)). Perhaps, it is due to high values of surface temperature. In this case, the heating of drop takes place rapidly, its temperature close to the boiling temperature. The evaporation process is more intensive, the diffusion increases with the droplet surface. It is found that after 30-50 seconds of the specific evaporation rate growth at investigation drop with maximum concentration (16.7\%) it decreases abruptly. This moment accompanied by formation of a massive "cover of a salt ring" around the perimeter of the drop and the almost complete drying up of the solvent (Fig. 7). Probably, this effect is the cause of lowering the rate.

In the first heating mode (Figs. 4-6(a)) when the concentration increases the specific evaporation rate became lower. It should be noted that the volume drops significantly affect the process. Decreasing of the specific evaporation rate depending on the volume and concentration in the first heating mode $(\mathrm{U}=5 \mathrm{~V}$; $\left.\mathrm{I}=2.8 \mathrm{~A} ; \mathrm{tw}=62.5^{\circ} \mathrm{C} ; \mathrm{ts}=61^{\circ} \mathrm{C}\right)$ are summarized in Table 3 , in the second heating mode $(\mathrm{U}=6 \mathrm{~B}$; 


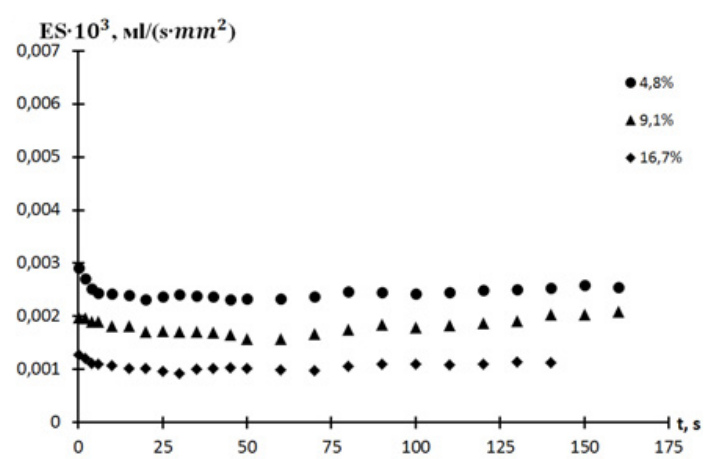

(a) $-\mathrm{U}=5 \mathrm{~V} ; \mathrm{I}=2.8 \mathrm{~A} ; \mathrm{t}_{\mathrm{w}}=62.5^{\circ} \mathrm{C} ; \mathrm{t}_{\mathrm{s}}=61^{\circ} \mathrm{C}$

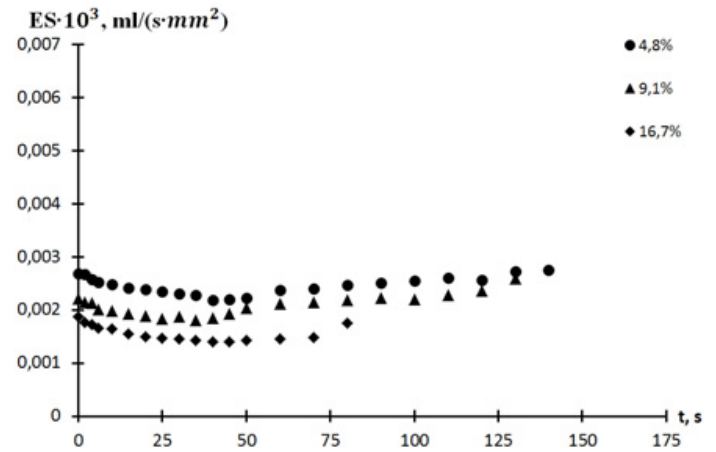

(b) $-\mathrm{U}=6 \mathrm{~V} ; \mathrm{I}=3.2 \mathrm{~A} ; \mathrm{t}_{\mathrm{w}}=73.5^{\circ} \mathrm{C} ; \mathrm{t}_{\mathrm{s}}=72.9^{\circ} \mathrm{C}$

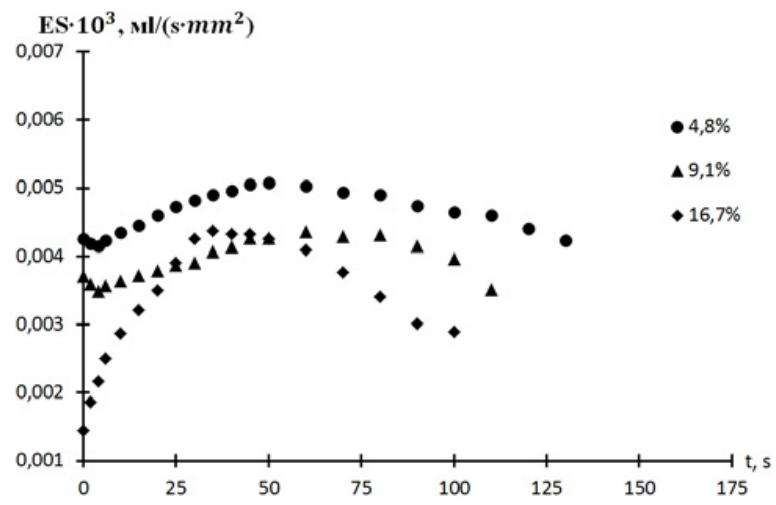

(c) $-\mathrm{U}=7 \mathrm{~V} ; \mathrm{I}=3.7 \mathrm{~A} ; \mathrm{t}_{\mathrm{w}}=84.5^{\circ} \mathrm{C} ; \mathrm{t}_{\mathrm{s}}=83.1^{\circ} \mathrm{C}$

Figure 6. Specific evaporation rate of water-sodium solution drop ( $\mathrm{V}=0.06 \mathrm{ml} ; \mathrm{c}=4.8 \% ; 9.1 \% ; 16.7 \%)$ on substrate made of anodized aluminum.

Table 3. Decreasing of the specific evaporation rate depending on the volume and concentration in the first heating mode.

\begin{tabular}{|l|c|c|}
\hline Concentration difference, $\%$ & Drop volume, $\mathbf{m l}$ & Decreasing of the specific evaporation rate, \% \\
\hline \multirow{3}{*}{$4.8-9.1$} & 0.02 & 7.1 \\
\cline { 2 - 3 } & 0.04 & 8.1 \\
\cline { 2 - 3 } & 0.06 & 32 \\
\hline \multirow{3}{*}{$4.8-16.7$} & 0.02 & 29 \\
\cline { 2 - 3 } & 0.04 & 41 \\
\cline { 2 - 3 } & 0.06 & 56 \\
\hline
\end{tabular}

$\left.\mathrm{I}=3.2 \mathrm{~A} ; \mathrm{tw}=73,5^{\circ} \mathrm{C} ; \mathrm{ts}=72,9^{\circ} \mathrm{C}\right)$ in Table 4 , in the third $\left(\mathrm{U}=7 \mathrm{~V} ; \mathrm{I}=3.7 \mathrm{~A} ; \mathrm{tw}=84.5^{\circ} \mathrm{C}\right.$; ts $=83.1^{\circ} \mathrm{C}$ ) in Table 5 .

In the third heating mode $\left(\mathrm{U}=7 \mathrm{~V} ; \mathrm{I}=3.7 \mathrm{~A}\right.$; tw $=84.5^{\circ} \mathrm{C}$; ts $\left.=83.1^{\circ} \mathrm{C}\right)$, the maximum surface temperature is achieved, respectively, the process time in this mode will be minimal. Thus, depending on the volume of droplet evaporation time in the first heating mode $\left(\mathrm{U}=5 \mathrm{~V} ; \mathrm{I}=2.8 \mathrm{~A} ; \mathrm{tw}=62.5^{\circ} \mathrm{C}\right.$; ts $\left.=61{ }^{\circ} \mathrm{C}\right)$ is $125-160 \mathrm{c}$, in the second mode $\left(\mathrm{U}=6 \mathrm{~B} ; \mathrm{I}=3.2 \mathrm{~A} ; \mathrm{tw}=73.5^{\circ} \mathrm{C}\right.$; ts $\left.=72.9^{\circ} \mathrm{C}\right)$ is $110-140 \mathrm{c}$, in the third mode is $90-130 \mathrm{c}$. 


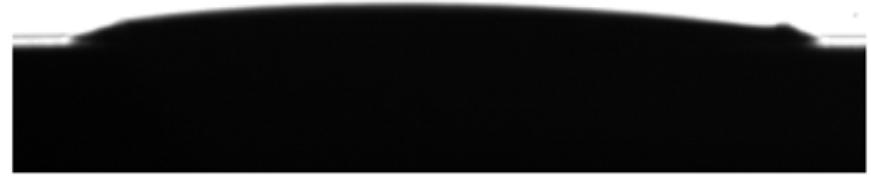

(a)

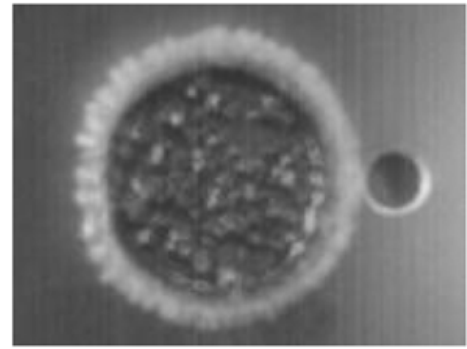

(b)

Figure 7. Photograph of evaporating droplet of saline solution $(\mathrm{V}=0.4 \mathrm{ml}, \mathrm{c}=16.7 \%)$ : $(\mathrm{a})$ - obtained by the shadow system; (b) - obtained by the Schlieren system.

Table 4. Decreasing of the specific evaporation rate depending on the volume and concentration in the second heating mode.

\begin{tabular}{|l|c|c|}
\hline Concentration difference, $\%$ & Drop volume, $\mathbf{m l}$ & Decreasing of the specific evaporation rate, \% \\
\hline \multirow{3}{*}{$4.8-9.1$} & 0.02 & 32.2 \\
\cline { 2 - 3 } & 0.04 & 23.4 \\
\cline { 2 - 3 } & 0.06 & 18.9 \\
\hline \multirow{3}{*}{$4.8-16.7$} & 0.02 & 47.5 \\
\cline { 2 - 3 } & 0.04 & 29.3 \\
\cline { 2 - 3 } & 0.06 & 63.5 \\
\hline
\end{tabular}

Table 5. Decreasing of the specific evaporation rate depending on the volume and concentration in the third heating mode.

\begin{tabular}{|l|c|c|}
\hline Concentration difference, \% & Drop volume, $\mathbf{~ m l}$ & Decreasing of the specific evaporation rate, \% \\
\hline \multirow{3}{*}{$4.8-9.1$} & 0.02 & 9.8 \\
\cline { 2 - 3 } & 0.04 & 32.7 \\
\cline { 2 - 3 } & 0.06 & 42.6 \\
\hline \multirow{3}{*}{$4.8-16.7$} & 0.02 & 41 \\
\cline { 2 - 3 } & 0.04 & 33.5 \\
\cline { 2 - 3 } & 0.06 & 63.5 \\
\hline
\end{tabular}

\section{Conclusion}

The effect of the initial concentration, surface temperature, droplet size on the specific evaporation rate has been estimated during the experimental study of the water-salt solution droplet evaporation. The dynamics of changes in the evaporation rate during the phase transition of the drop has been defined.

\section{References}

[1] Sreznevsky V., Beibl Ann, Phys Chem 7, 888 (1883)

[2] Morse H.W., Proc Am Acad Arts Sci 45, 363 (1910)

[3] Yalamov Y.I., Kuzmin M.K., Reports of the Academy of Sciences, 392 (1), 44 (2003)

[4] Yalamov Y.I., Kuzmin M.K., Technical Physics 75 (3), 30 (2005)

[5] King M.D., Yang J.C., Chien W.S., Grosshandler W.L., Proceedings of the ASME National Heat Transfer Conference, Baltimore, USA, 1997

[6] Saverchenko V.I., Fisenko S.P., Khodiko Yu.A., IFZh 84 (4), 670 (2011)

[7] Yu H.Z., Soolaman D.M., Rowe A.W., Banks J.T., Chemphyschem., 5, 1035 (2004) 
[8] Shanahan M.E.R., Bourges C., Int. J. Adhesion Adhesives, 14 (3), 201 (1994)

[9] Guena G., Poulard C., Voue M., De Coninck J., Cazabat A.M., Colloids Surf A. 291, 191 (2006)

[10] Poulard C., Benichou O., Cazabat A.M., Langmuir 19, 8828 (2003)

[11] King M.D., Yang J.C., Chien W.S., Grosshandler W.L., Proceedings of the ASME National Heat Transfer Conference, Baltimore, USA, 1997

[12] Deegan R. D., Bakajin O., Dupont T.F., Huber G., Sidney., Nature 389, 137 (1997)

[13] Deegan R.D. et al., Phys. Rev. E., 62, 756 (2000)

[14] Deegan R.D., Phys. Rev. E., 61, 475 (2000)

[15] Grishaev V., Amirfazli A.,•Chikov S., Lyulin Y., Kabov O., Microgravity Sci. Technol. 25, 27 (2013)

[16] Marchuk I., Lyulin Y., Kabov O., Interfacial Phenomena and Heat Transfer 1 (2), 153 (2013)

[17] Goncharova O.N., Hennenberg M., Rezanova E.V., Kabov O.A., Interfacial Phenomena and Heat Transfer 1 (4), 317 (2013)

[18] Gatapova E. Ya., Semenov A. A., Zaitsev D. V., Kabov O. A., Colloids and Surfaces A: Physicochem. Eng. Aspects. 441, 776 (2014) 